\title{
The basolateral amygdala is necessary for learning but not relearning extinction of context conditioned fear
}

\author{
Vincent Laurent, ${ }^{1,2}$ Alain R. Marchand, ${ }^{2}$ and R. Frederick Westbrook ${ }^{1,3}$ \\ ${ }^{1}$ School of Psychology, The University of New South Wales, Sydney, New South Wales 2052, Australia; ${ }^{2}$ Centre de Neurosciences \\ Intégratives et Cognitives, UMR 5228, CNRS, F-33405 Talence Cedex, France
}

\begin{abstract}
Extinction of conditioned fear involves new learning that inhibits but does not eliminate the original fear memory. This inhibitory learning is thought to require activation of NMDA receptors (NMDAr) within the basolateral amygdala (BLA). However, once extinction has been learned, the role played by the BLA during subsequent extinction procedures remains unknown. The present study examined the role of neuronal activity and NMDAr activation in rats receiving their first or second extinction of context fear. We found that BLA infusion of DL-APV, a competitive antagonist of NMDAr, depressed fear responses at both the first and second extinction. It impaired learning extinction but spared and even facilitated relearning extinction. BLA infusion of muscimol, a $G A B A_{A}$ agonist, produced a similar outcome, suggesting that DL-APV not only blocked NMDAr-dependent plasticity but also disrupted neuronal activity. In contrast, infusion of ifenprodil, a more selective antagonist of NMDAr containing the NR2B subunit, did not depress fear responses but impaired short- and long-term inhibition of fear at both the first and second extinction. Therefore, we suggest that relearning extinction normally requires NMDAr containing the NR2B subunit in the BLA. However, simultaneous blockade of these receptors and neuronal activity in the BLA results in compensatory learning that is able to promote long-term re-extinction. These data are consistent with a current model that attributes fear extinction to interactions between several neural substrates, including the amygdala and the medial prefrontal cortex.
\end{abstract}

Processes by which subjects learn to inhibit inappropriate fear reactions are of considerable interest for human clinical research (Milad et al. 2006; Myers and Davis 2007). Extinction of Pavlovian conditioned fear is a laboratory model aimed at understanding how organisms adjust to changes in environmental sources of danger. Subjects (e.g., rats) initially learn that a place (i.e., context) or stimulus (i.e., cue) signals brief but aversive stimulation (e.g., foot shock). Then they are repeatedly exposed to the now conditioned place or stimulus (CS) in the absence of the aversive foot shock unconditioned stimulus (US). The fear responses (e.g., freezing) produced by the signaling relation decrease across CS alone exposures and eventually cease to occur. Fear responding to the CS is said to be extinguished. In spite of the fact that the CS fails to elicit fear responses, the original conditioning remains intact. For instance, fear responses are restored with the passage of time (spontaneous recovery), a shift in context (renewal) or US alone presentations (reinstatement) (Bouton et al. 2006). These response restoration phenomena have led to the view that extinction involves new learning that coexists with the original conditioning but inhibits its expression in fear responses (Delamater 2004; Myers et al. 2006; Quirk and Mueller 2007). Retraining the CS-US relation after extinction restores fear responses but similarly spares the inhibition learned in extinction, as phenomena such as spontaneous recovery and renewal remain intact in spite of the fact that the CS now elicits responding (Bouton and Swartzentruber 1989; Rescorla 2001). Thus, relearning the CS-US relation leaves intact the learning produced by extinction but removes its inhibition of fear responding. Most of these results have been described with an ex-

${ }^{3}$ Corresponding author.

E-mail f.westbrook@unsw.edu.au; fax 61-92-03853044.

Article is online at http://www.learnmem.org/cgi/doi/10.1101//m.928208. plicit cue as the CS, but there is also evidence for similar phenomena during extinction of context fear (Leung et al. 2007).

A substantial body of research suggests that neuronal activity in the amygdala and the medial prefrontal cortex (mPFC) mediate the opposition between excitation and inhibition of fear responses. Fear acquisition occurs in the lateral and basolateral regions of the amygdala (BLA), where the association between incoming information about the CS and US potentiates synaptic transmission (Maren 2001; Rodrigues et al. 2004). The lateral region appears more involved in cued fear, whereas the basolateral region is more involved in context fear (Calandreau et al. 2005). These regions project to neurons in the central nucleus (CeA) that coordinate the components of the fear response via efferent projections to diencephalic and brainstem structures (Sah et al. 2003). Fear extinction is also critically dependent upon the BLA. For instance, local blockade of NMDA receptors (NMDAr), metabotropic glutamate receptors, or mitogen-activated protein kinase (MAPk) activity impairs the acquisition of extinction (Herry et al. 2006; Kim et al. 2007; Sotres-Bayon et al. 2007). Moreover, the consolidation of extinction requires activation in the BLA of the phosphoinositide-3 kinase pathway, synthesis of new protein, and the expression of immediate early genes (IEGs) (Lin et al. 2003; Herry and Mons 2004). The mPFC also contributes to the consolidation of extinction. Blockade of NMDAr, MAPk, or protein synthesis spares the acquisition but impairs the retention of extinction (Hugues et al. 2004, 2006; Santini et al. 2004; Burgos-Robles et al. 2007). Furthermore, extinction training is followed by an increase of glucose metabolism and expression of IEG in the mPFC (Barrett et al. 2003; Herry and Mons 2004). Once extinction is acquired, the mPFC appears to constitute the substrate underlying subsequent activation of inhibitory mechanisms in the BLA. For instance, single unit recordings have revealed that neurons in the $\mathrm{MPFC}$ exhibit enhanced firing to an 
extinguished CS (Milad and Quirk 2002). Moreover, stimulation of the mPFC reduces conditioned fear responses (Milad et al. 2004) and inhibits the activity of CeA efferent neurons mediating these responses (Quirk et al. 2003). It has been suggested that this inhibition occurs via projections from the MPFC to a network of GABAergic cells located between the BLA and CeA (Quirk et al. 2003; Quirk and Mueller 2007).

Taken together, these data indicate that the BLA is required for learning inhibition of fear across extinction, while the mPFC controls activation of inhibitory mechanisms in the amygdala that suppress fear responses to the extinguished CS. The present series of experiments assessed whether the BLA was required for learning and relearning to inhibit context conditioned fear responses in extinction. Since retraining the CS-US association leaves intact extinction learning while removing its inhibitory influence on fear responding, we reasoned that synaptic plasticity in the BLA might not be necessary to relearn extinction, provided the mPFC can re-exert its control over fear responding. We investigated the conditions under which relearning could proceed in the absence of synaptic plasticity in the BLA. We compared rats submitted to two cycles of context fear conditioning and extinction with control rats treated in the same way except that the first extinction session was omitted. Rats received their second extinction (re-extinction) under a BLA infusion of drug or vehicle, while those in the control group received their first extinction under a BLA infusion of drug or vehicle. All rats were tested drug free for retention of the learning produced by extinction or re-extinction. We first studied the effects of DL-2-amino-5-phosphonopentanoic acid (DL-APV), a competitive antagonist of NMDAr, and then investigated the contribution of BLA synaptic activity or plasticity by means of the $\mathrm{GABA}_{\mathrm{A}}$ agonist muscimol and by ifenprodil, an antagonist for the NR2B subunit of the NMDAr.

\section{Results}

\section{Experiment 1: BLA infusion of DL-APV impairs learning} but not relearning extinction

Previous investigations revealed that infusion of DL-APV in the BLA reduces conditioned fear responses and impairs long-term extinction (Lee and Kim 1998; Lee et al. 2001). We examined whether a similar treatment impairs relearning extinction of context conditioned fear. Rats were bilaterally implanted with cannulae targeting the BLA and were randomly assigned to one of the three experimental conditions (see Fig. 2A). Rats in groups Re-extinction were submitted to context fear conditioning on days 1 and 3 , and to extinction on days 2 and 4 . The re-extinction session on day 4 was performed under BLA infusion of either vehicle (group Re-extinctionVehicle) or DL-APV (group Re-extinction-APV). Rats in groups Extinction received the same procedure except that the initial extinction session on day 2 was omitted. Thus, no extinction occurred until day 4 . The other control groups (groups Control Re-extinction) were intended to test the effects of DL-APV infusion per se. They were treated similarly to groups Re-extinction and received the BLA infusion of DL-APV or vehicle on day 4 but without the re-extinction session. Longterm extinction and long-term re-extinction were assessed in all rats across a retention test given on day 5 .

\section{Histology}

Figure $1 \mathrm{~A}$ shows the location of microinjection tips. A total of six rats were excluded because of incorrect cannula placement. This yielded the following group sizes: Extinction-Vehicle $(n=7)$, Extinction-APV $(n=6)$, Re-extinction-Vehicle $(n=7)$, Re-extinction-APV $(n=8)$, Control Re-extinction-Vehicle $(n=7)$, and Control Re-extinction-APV $(n=7)$.

\section{Behavior}

Levels of conditioned freezing to the context across extinction, re-extinction, and test are shown in Figure 2. The conditioning episode given on day 1 was successful. Rats in groups Reextinction and Control Re-extinction exhibited substantial levels of freezing when returned to the context for extinction on day 2 (Fig. 2B). These levels significantly declined over the course of the session $\left(F_{(1,25)}=137.365 ; P<0.05\right)$. On day 3 , these rats showed long-term retention of extinction (data not shown). They froze significantly less before the shock than rats that had not yet received any extinction (groups Extinction) $\left(F_{(1,36)}=5.239\right.$; $P<0.05)$. This shock given on day 3 restored extinguished fear
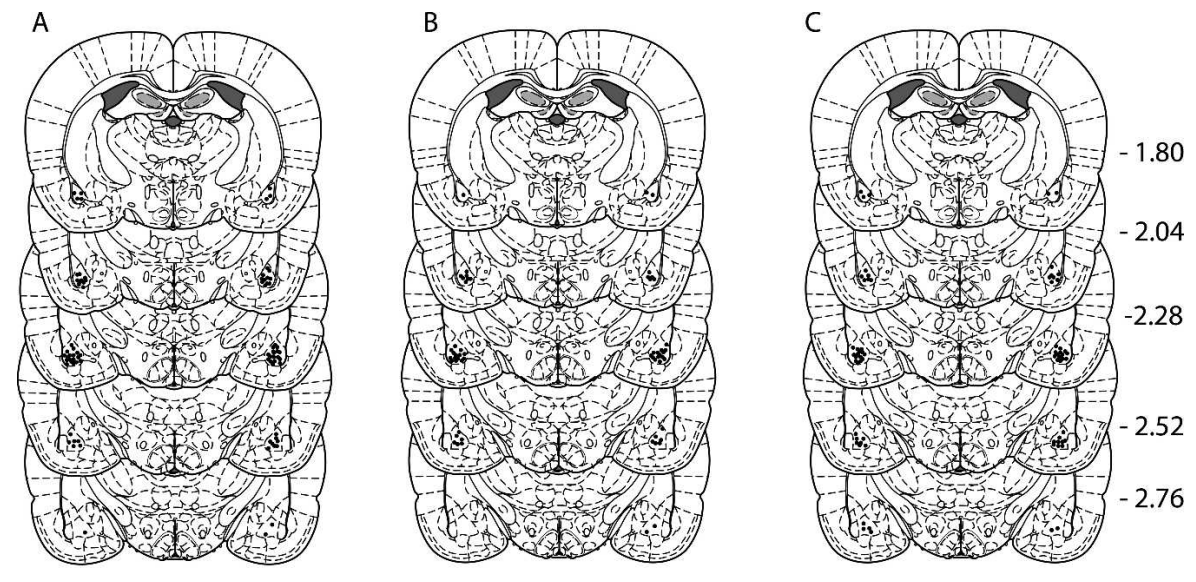

$\mathrm{D}$
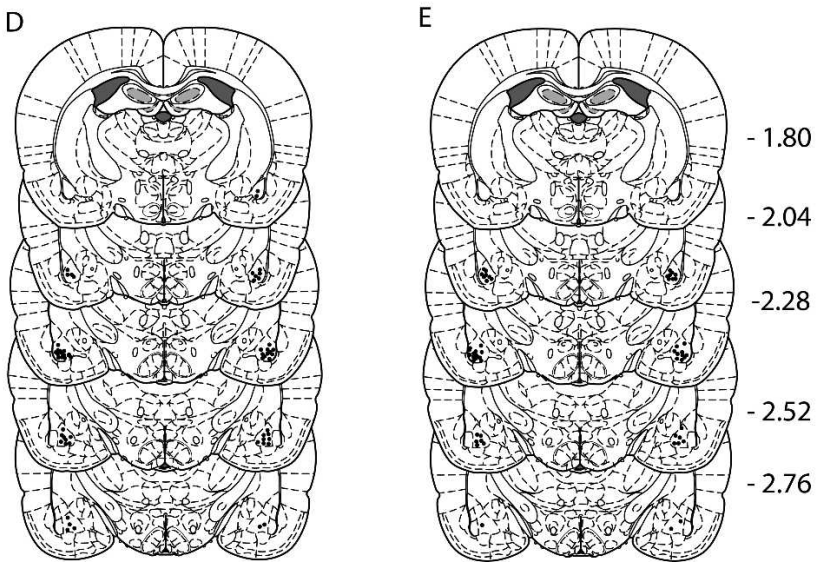

Figure 1. Location of microinjection cannula within the BLA for all rats included in the final analysis of experiments $1(A), 2(B), 3(C), 4(D)$, and $5(E)$. Distances on the atlas templates (adapted from Paxinos and Watson 2007) are indicated in millimeters from bregma. 
A

\begin{tabular}{lccccc}
\multicolumn{1}{|c}{ Groups } & Day 1 & Day 2 & Day 3 & Day 4 & Day 5 \\
\hline $\begin{array}{l}\text { Extinction } \\
\text { (Ext) }\end{array}$ & + & & + & Vehicle orAPV & - \\
$\begin{array}{l}\text { Re-extinction } \\
\text { (Re-ext) }\end{array}$ & + & - & + & $\begin{array}{c}\text { Vehicle orAPV } \\
-\end{array}$ & - \\
$\begin{array}{l}\text { Control Re-extinction } \\
\text { (Ctrl Re-ext) }\end{array}$ & + & - & + & Vehicle orAPV & - \\
\hline
\end{tabular}

B



C



D

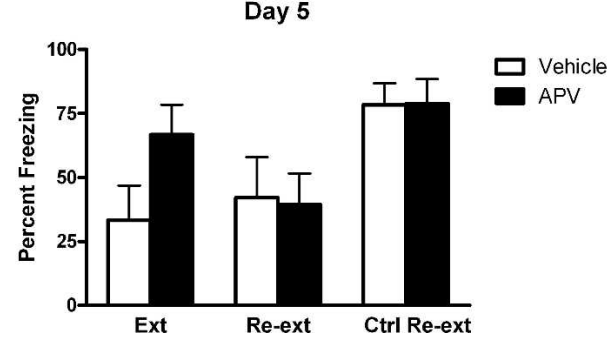

Figure 2. BLA infusion of DL-APV impairs learning but not relearning extinction. $(A)$ Description of the behavioral procedures used in Experiment $1(+$, shocked exposure to the chambers; -, non-shocked exposure to the chambers). (B) All illustrations show the mean and SEM levels of freezing. Rats in groups Re-extinction and Control-Re-extinction lost freezing responses across initial extinction. (C) BLA infusions of DL-APV depressed freezing across extinction and re-extinction. Extinction and re-extinction were similar in control rats. $(D)$ The retention test showed that DL-APV impaired extinction learning (group Extinction-APV) but not relearning extinction (group Re-extinction-APV). Retention of extinction and re-extinction learning was similar in control rats.

responses. Robust fear responses were observed on day 4 in both groups during exposure to the context for extinction or re-extinction (Fig. 2C). Rats in group Re-extinction-Vehicle froze just as much as did rats in group Extinction-Vehicle $\left(F_{(1,24)}=0.042 ; P>0.05\right)$. BLA infusion of DL-APV significantly reduced freezing responses over the course of the session in groups Extinction-APV and Re-extinction-APV compared with groups Extinction-Vehicle and Re-extinction-Vehicle $\left(F_{(1,24)}=29.418 ; P<0.05\right)$. Groups that received DL-APV did not differ significantly from each other $\left(F_{(1,24)}=0.106 ; P>0.05\right)$. Overall, levels of freezing significantly decreased across the session $\left(F_{(1,24)}=123.750 ; P<0.05\right)$.

The retention test data (Fig. 2D) revealed that BLA infusion of DL-APV impaired learning extinction but not relearning extinction of conditioned fear responses. Rats in group ExtinctionAPV froze significantly more that rats in group ExtinctionVehicle $\left(F_{(1,36)}=10.713 ; P<0.05\right)$. In contrast, there were no significant differences between the levels of freezing displayed by rats in groups Re-extinction-Vehicle and Re-extinction-APV $\left(F_{(1,36)}=0.083 ; P>0.05\right)$. In addition, rats in groups ExtinctionAPV froze significantly more than rats in groups Re-extinction$\operatorname{APV}\left(F_{(1,36)}=7.609 ; P<0.05\right)$, although rats in groups Extinction-Vehicle and Re-extinction-Vehicle did not differ significantly $\left(F_{(1,36)}=0.808 ; P>0.05\right)$. This indicates that the first extinction was significantly more affected by DL-APV than reextinction. The infusion of DL-APV by itself was without effect since rats in groups Control Re-extinction that had been extinguished but not re-extinguished showed equivalent levels of freezing whether they were infused in the BLA with either vehicle or DL-APV $\left(F_{(1,36)}=0.002 ; P>0.05\right)$.

\section{Experiment 2: BLA infusion of DL-APV does not spare relearning extinction if initial extinction learning has been prevented}

Experiment 1 showed that BLA infusion of DL-APV impairs learning extinction but not relearning extinction. Accordingly, we suggest that a memory of the original extinction training is reactivated across re-extinction and thereby promotes the longterm loss of fear responses. If the first extinction training is performed under APV, this memory should be impaired. Therefore, this manipulation should restore the sensitivity of the second extinction session to APV infusion. The present experiment tested this suggestion by examining the effects of DL-APV infusion during the first or second extinction session as well as during both sessions. Four groups of rats (Fig. 3A) were trained to fear a context on day 1 and were submitted to an extinction session on day 2 under BLA infusion of either vehicle or APV. Then all rats were retrained to fear the context on day 3 and received another extinction session under BLA infusion of either vehicle (groups Vehicle-Vehicle and APV-Vehicle) or APV (groups Vehicle-APV and APV-APV) on day 4. Levels of conditioned performances were assessed across a retention test conducted on day 5 .

\section{Histology}

Figure $1 \mathrm{~B}$ shows the location of microinjection tips. A total of four rats were excluded because of incorrect cannula placement. This yielded the following group sizes: Vehicle-Vehicle $(n=7)$, Vehicle-APV $(n=6)$, APV-Vehicle $(n=7)$, and APV-APV $(n=8)$.

\section{Behavior}

Levels of conditioned freezing to the context across extinction, re-extinction, and test are shown in Figure 3. Rats under infusion of vehicle displayed substantial levels of freezing when returned to the context for extinction on day 2 (Fig. 3B, groups VehicleVehicle and Vehicle-APV). Rats under infusion of DL-APV (groups APV-Vehicle and APV-APV) showed reduced freezing responses with respect to rats treated with vehicle $\left(F_{(1,24)}=47.963\right.$; $P<0.05)$. The levels of freezing displayed by all rats declined across the session $\left(F_{(1,24)}=62.771 ; P<0.05\right)$. On day 3 , the freez- 
ing responses observed before the shock showed that BLA infusion of DL-APV impaired extinction learning (data not shown). Rats that had received DL-APV before extinction on day 2 (groups

A

\begin{tabular}{|c|c|c|c|c|c|}
\hline Groups & Day 1 & Day 2 & Day 3 & Day 4 & Day 5 \\
\hline $\begin{array}{l}\text { Vehicle - Vehicle } \\
\text { (VEH - VEH) }\end{array}$ & + & $\begin{array}{c}\text { Vehicle } \\
-\end{array}$ & + & $\begin{array}{c}\text { Vehicle } \\
-\end{array}$ & - \\
\hline $\begin{array}{l}\text { Vehicle-APV } \\
\text { (VEH-APV) }\end{array}$ & + & $\begin{array}{c}\text { Vehicle } \\
\text { - }\end{array}$ & + & $\begin{array}{l}\text { APV } \\
-\end{array}$ & - \\
\hline $\begin{array}{l}\text { APV - Vehicle } \\
\text { (APV - VEH) }\end{array}$ & + & $\begin{array}{c}\text { APV } \\
-\end{array}$ & + & $\begin{array}{c}\text { Vehicle } \\
-\end{array}$ & - \\
\hline $\begin{array}{l}\text { APV - APV } \\
\text { (APV-APV) }\end{array}$ & + & $\begin{array}{c}\text { APV } \\
-\end{array}$ & + & $\begin{array}{c}\text { APV } \\
-\end{array}$ & - \\
\hline
\end{tabular}

B

Day 2

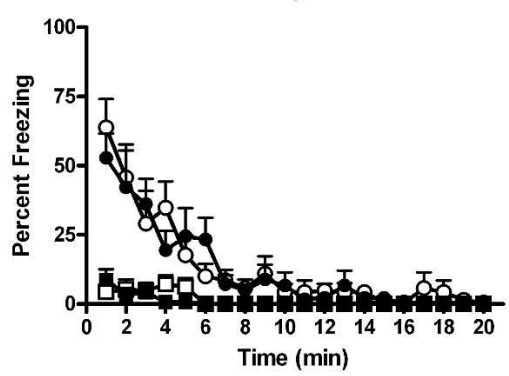

C

Day 4

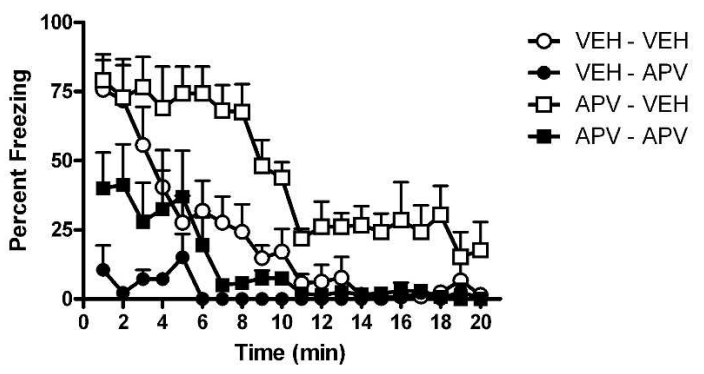

D

Day 5

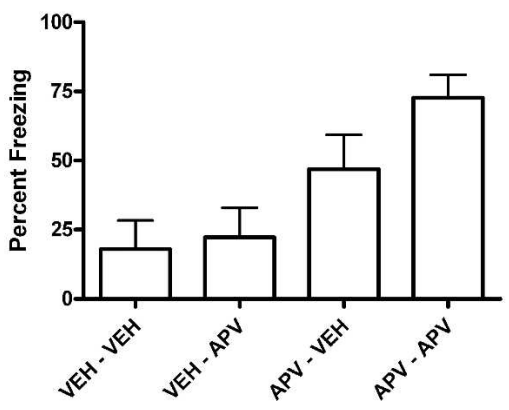

Figure 3. BLA infusion of DL-APV does not spare relearning extinction if initial extinction learning has been prevented. $(A)$ Description of the behavioral procedures used in Experiment $2(+$, shocked exposure to the chambers; -, non-shocked exposure to the chambers). (B) All illustrations show the mean and SEM levels of freezing. BLA infusion of DL-APV depressed freezing responses across extinction (groups APV-Vehicle and APV-APV) and re-extinction (C; groups Vehicle-APV and APV-APV). (D) The retention test showed that DL-APV impaired extinction learning (groups APV-Vehicle and APV-APV) and relearning extinction when there had been no initial extinction learning (group APV-APV).
APV-Vehicle and APV-APV) froze significantly more during this period than rats that had received vehicle (groups VehicleVehicle and Vehicle-APV) $\left(F_{(1,24)}=16.087 ; P<0.05\right)$. This shock restored extinguished fear responses on day 4 as revealed by the substantial levels of freezing displayed by control rats returned to the context for re-extinction (Fig. 3C, group Vehicle-Vehicle). However, these rats froze significantly less than those in group APV-Vehicle $\left(F_{(1,24)}=14.444 ; P<0.05\right)$, confirming that the latter had failed to learn the initial extinction under APV. DL-APV infused in the BLA also depressed fear responses across reextinction. Rats in groups Vehicle-APV and APV-APV froze significantly less than rats in groups Vehicle-Vehicle and APVVehicle $\left(F_{(1,24)}=32.132 ; P<0.05\right)$. There was no significant difference among groups of rats treated with DL-APV across the entire re-extinction session $\left(F_{(1,24)}=2.149 ; P>0.05\right)$. Nevertheless, rats in group APV-APV tended to freeze more than rats in group Vehicle-APV at the start of the session. Although this tendency did not reach significance $\left(F_{(1,24)}=3.029 ; P>0.05\right.$, separate analysis on the first five minutes of the session), it suggests once again that initial extinction learning was prevented by DLAPV (group APV-APV) compared with vehicle (group VehicleAPV). Finally, re-extinction induced a significant decrease of freezing across the session $\left(F_{(1,24)}=49.845 ; P<0.05\right)$.

The test data on day 5 (Fig. 3C) show that infusion of DLAPV during the initial extinction session impaired extinction learning. Rats infused with DL-APV prior to this session (groups APV-Vehicle and APV-APV) displayed higher levels of freezing than rats infused with vehicle $\left(F_{(1,24)}=30.477 ; P<0.05\right)$. These data also confirm that rats who had learned extinction under vehicle relearned extinction just as effectively under DL-APV as under vehicle. Rats in group Vehicle-APV froze just as much as did rats in group Vehicle-Vehicle $\left(F_{(1,24)}=0.206 ; P>0.05\right)$. However, infusion of DL-APV prior to both sessions impaired the learning produced by re-extinction. Rats in group APV-APV froze significantly more than rats in group APV-Vehicle $\left(F_{(1,24)}=\right.$ 9.134; $P<0.05)$. Thus, rats for which the first extinction session had been performed under APV remained sensitive to APV treatment during re-extinction.

\section{Experiment 3: BLA infusion of DL-APV facilitates relearning extinction}

Experiment 2 revealed that BLA infusion of DL-APV spares longterm re-extinction only if extinction had been previously learned. This is consistent with the suggestion that the extinction memory is reactivated when re-extinction training occurs under BLA infusion of DL-APV. If so, even a brief re-extinction session might be sufficient for such a reactivation to occur. The present experiment examined whether learning re-extinction under APV depended on the length of the re-extinction training (Fig. 4B). Rats were trained to fear a context on day 1 and submitted to an extinction session on day 2. They were retrained to fear the context on day 3 and submitted to a re-extinction session on day 4 under BLA infusion of either vehicle or APV. For some rats, the re-extinction session lasted 2 min (groups 2 min-Vehicle and 2 min-APV), whereas for the remaining rats it lasted $20 \mathrm{~min}$ as in the previous experiments (groups 20 min-Vehicle and 20 minAPV). Long-term re-extinction was assessed across a retention test on day 5.

\section{Histology}

Figure 1C shows the location of microinjection tips. A total of nine rats were excluded because of incorrect cannula placement. This yielded the following group sizes: 2 min-Vehicle $(n=11), 2$ 
A

\begin{tabular}{|cccccc}
\hline Groups & Day 1 & Day 2 & Day 3 & Day 4 & Day 5 \\
\hline $2 \min$ & + & - & + & $\begin{array}{c}\text { Vehicle orAPV } \\
2^{\prime}-\end{array}$ & - \\
$20 \mathrm{~min}$ & + & - & + & $\begin{array}{c}\text { Vehicle orAPV } \\
20^{\prime}-\end{array}$ & - \\
\hline
\end{tabular}

B

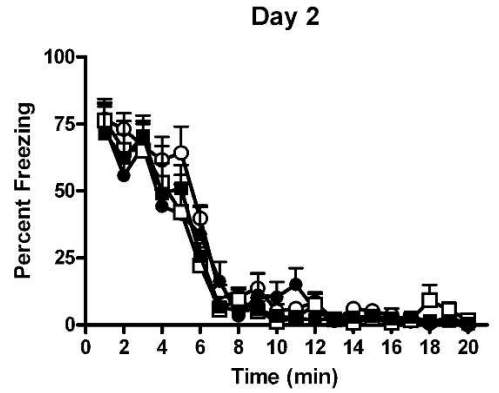

C



D

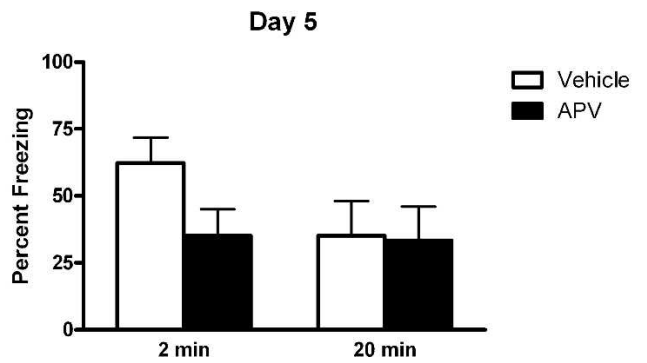

Figure 4. BLA infusion of DL-APV facilitates relearning extinction. (A) Description of the behavioral procedures used in Experiment $3(+$, shocked exposure to the chambers; - , non-shocked exposure to the chambers). (B) All illustrations show the mean and SEM levels of freezing. All rats lost freezing responses across initial extinction. (C) BLA infusion of DL-APV depressed freezing across re-extinction. $(D)$ The retention test showed that DL-APV not only spared (group 20 min-APV) but facilitated relearning extinction (group 2 min-APV).

min-APV $(n=10), 20$ min-Vehicle $(n=8)$, and 20 min-APV $(n=7)$.

\section{Behavior}

Levels of conditioned freezing to the context across extinction, re-extinction, and test are shown in Figure 4. All rats showed substantial levels of freezing when returned to the context on day 2 (Fig. 4B), and these levels declined across the extinction session $\left(F_{(1,32)}=273.411 ; P<0.05\right)$. Extinguished fear responses were restored by the reconditioning episode given on day 3 (data not shown). Indeed, when returned to the context on day 4 , rats in groups $2 \mathrm{~min}-$ Vehicle and $20 \mathrm{~min}-V e h i c l e ~ e x h i b i t e d ~ s u b s t a n-$ tial levels of fear responses (Fig. 4C). DL-APV reduced fear reactions. Rats in groups 2 min-APV and 20 min-APV froze significantly less than vehicle-treated rats during the first two minutes $\left(F_{(1,32)}=194.105 ; P<0.05\right)$. A separate analysis of freezing levels for rats subjected to the 20 min re-extinction session confirmed this effect of DL-APV over the whole session $\left(F_{(1,13)}=142.102\right.$; $P<0.05)$. Freezing declined across the session $\left(F_{(1,13)}=164.760\right.$; $P<0.05)$.

The test data (Fig. 4D) can be described succinctly. Rats subjected to a brief re-extinction session under vehicle (group 2 minVehicle) froze significantly more (i.e., showed less re-extinction) than the remaining rats (groups 20 min-Vehicle, 20 min-APV, and 2 min-APV) $\left(F_{(1,32)}=22.468 ; P<0.05\right)$. In rats that received a 20-min re-extinction session, DL-APV infusion had no effect

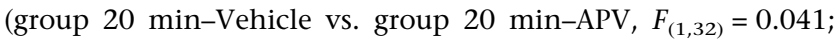
$P>0.05)$. Importantly, under DL-APV, a 2-min re-extinction session or a 20 -min re-extinction session did not yield significantly different results (groups 2 min-APV vs. 20 min-APV, $\left.F_{(1,32)}=0.048 ; P>0.05\right)$. Thus, re-extinction learning during a brief session was facilitated by the BLA infusion of DL-APV.

\section{Experiment 4: BLA infusion of muscimol impairs learning but not relearning extinction}

The previous experiments demonstrated that BLA infusion of DL-APV prevents long-term extinction but facilitates long-term re-extinction. Electrophysiological studies have shown that DLAPV not only interferes with NMDAr-dependent synaptic plasticity but also disrupts basal synaptic transmission in the BLA (Li et al. 1995; Maren and Fanselow 1995; Bauer et al. 2002). This disruption results in an impairment of fear reactions similar to the one we observed across extinction training and re-extinction training (Lee and Kim 1998; Lee et al. 2001). These findings suggest that DL-APV might exert its effects not only through a blockade of NMDAr dependent plasticity but also through a disruption of neuronal activity in the BLA. Consequently, inactivation of the BLA with muscimol during learning or relearning extinction could have the same effects as DL-APV infusion. The purpose of Experiment 4 was to test this hypothesis with a design analogous to Experiment 1 (Fig. 5A). Rats in groups Re-extinction were conditioned to fear a context on day 1 and day 3 , and submitted to extinction on day 2 and day 4 . The re-extinction session on day 4 was performed under BLA infusion of either vehicle (group Re-extinction-Vehicle) or muscimol (group Re-extinctionMuscimol). Rats in groups Extinction received the same procedure except that the initial extinction session on day 2 was omitted. Long-term extinction and long-term re-extinction were assessed in all rats across a retention test given on day 5 .

\section{Histology}

Figure 1D shows the location of microinjection tips. A total of four rats were excluded because of incorrect cannula placement. This yielded the following group sizes: Extinction-Vehicle $(n=6)$, Extinction-Muscimol $(n=7)$, Re-extinction-Vehicle $(n=7)$, and Re-extinction-Muscimol $(n=7)$.

\section{Behavior}

Levels of conditioned freezing to the context across extinction, re-extinction, and test are shown in Figure 5. The conditioning episode given on day 1 was successful, as rats returned to the 
A

\begin{tabular}{lccccc}
\multicolumn{1}{c}{ Groups } & Day 1 & Day 2 & Day 3 & Day 4 & Day 5 \\
\hline $\begin{array}{l}\text { Extinction } \\
\text { (Ext) }\end{array}$ & + & & + & Vehicle or Muscimol & - \\
$\begin{array}{l}\text { Re-extinction } \\
\text { (Re-ext) }\end{array}$ & + & - & + & Vehicle or Muscimol & - \\
\hline
\end{tabular}

B

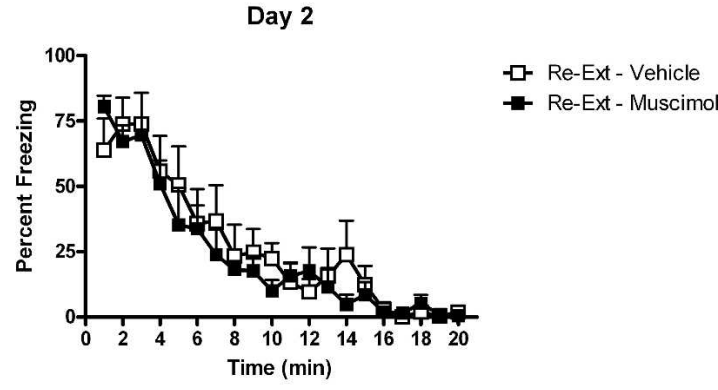

C

Day 4


D

Day 5

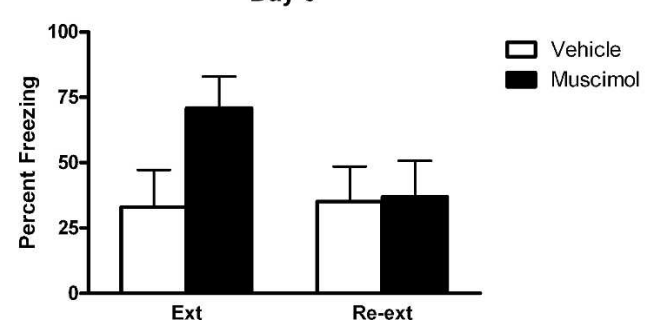

Figure 5. BLA infusion of muscimol impairs learning but not relearning extinction. (A) Description of the behavioral procedures used in Experiment $4(+$, shocked exposure to the chambers; - , non-shocked exposure to the chambers). (B) All illustrations show the mean and SEM levels of freezing. Rats in groups Re-extinction lost freezing responses across extinction. (C) Muscimol depressed freezing responses across extinction and re-extinction. $(D)$ The retention test showed that muscimol impaired extinction learning (group Extinction-Muscimol) but not relearning extinction (group Re-extinction-Muscimol). Retention of extinction and reextinction learning was similar in control rats.

context on day 2 displayed substantial freezing (Fig. 5B, groups Re-Extinction). Freezing decreased across the extinction session $\left(F_{(1,12)}=82.952 ; P<0.05\right)$, and extinction was retained, since on day 3 rats that had undergone extinction froze significantly less than the other rats during the period prior to shock (groups Reextinction vs. groups Extinction, $F_{(1,23)}=21.515 ; P>0.05$ ) (data not shown). The reconditioning episode given on day 3 restored fear responses that had been extinguished. Indeed, when returned to the context on day 4 (Fig. 5C), vehicle-treated rats showed substantial levels of freezing whether or not they had undergone extinction (group Re-extinction-Vehicle vs. group Extinction-Vehicle, $\left.F_{(1,23)}=0.26 ; P>0.05\right)$. Muscimol infused in the BLA significantly reduced the levels of fear responses $\left(F_{(1,23)}=40.470 ; P<0.05\right)$. Although all muscimol-treated rats showed comparably low levels of fear reactions $\left(F_{(1,23)}=0.135\right.$; $P>0.05)$, there was a significant linear trend, showing that freezing declined across the session $\left(F_{(1,23)}=185.301 ; P<0.05\right)$.

During test on day 5 (Fig. 5D), the data revealed that rats that had received a single extinction session under muscimol froze significantly more that their vehicle-treated controls (group Extinction-Muscimol vs. group Extinction-Vehicle, $\left.F_{(1,23)}=8.636 ; P<0.05\right)$. Thus, muscimol-induced inactivation of the BLA impaired learning extinction. In contrast, learning reextinction was spared. There were no significant differences in levels of freezing between rats in groups Re-extinction-Muscimol and Re-extinction-Vehicle $\left(F_{(1,23)}=0.021 ; P>0.05\right)$. Moreover, rats in group Extinction-Muscimol froze significantly more than rats in group Re-extinction-Muscimol $\left(F_{(1,24)}=7.574 ; P<0.05\right)$, whereas vehicle-treated rats showed comparable levels of freezing irrespective of the first extinction treatment (group Reextinction-Vehicle vs. Extinction-Vehicle, $\left(F_{(1,23)}=0.024\right.$; $P>0.05)$.

\section{Experiment 5: BLA infusion of ifenprodil impairs both learning and relearning extinction}

Experiment 4 showed that muscimol-induced inactivation of the BLA replicates the effects of BLA infusion of DL-APV on learning and relearning extinction. That is, both drugs depressed fear responses across extinction training and re-extinction training. Furthermore, they impaired long-term extinction while leaving intact long-term re-extinction. These results suggest that DL-APV acted via disruption of both neuronal activity and NMDArdependent plasticity in the BLA (Li et al. 1995; Maren and Fanselow 1995; Bauer et al. 2002). To further confirm this, experiment 5 investigated the effects of ifenprodil, a selective antagonist of NMDAr containing the NR2B subunit, on learning and relearning extinction. Unlike DL-APV or muscimol, ifenprodil spares neuronal activity in the amygdala (Bauer et al. 2002) and the expression of fear responses (Rodrigues et al. 2001; Sotres-Bayon et al. 2007). This experiment used the same design as Experiment 4 (Fig. 6A) except that rats were infused with either vehicle (group Extinction-Vehicle and Re-extinction-Vehicle) or ifenprodil (group Extinction-Ifenprodil and Re-extinctionIfenprodil) prior to being submitted to extinction on day 4 .

\section{Histology}

Figure 1E shows the location of microinjection tips. A total of five rats were excluded because of incorrect cannula placement. This yielded the following group sizes: Extinction-Vehicle $(n=6)$, Extinction-Ifenprodil $(n=6)$, Re-extinction-Vehicle $(n=7)$, and Re-extinction-Ifenprodil $(n=7)$.

\section{Behavior}

Levels of conditioned freezing to the context across extinction, re-extinction, and test are shown in Figure 6. On day 2, there was substantial freezing when rats in groups Re-extinction were returned to the context for extinction training (Fig. 6B), and freezing declined across the session $\left(F_{(1,11)}=35.521 ; P<0.05\right)$. Although rats in groups Re-extinction froze significantly less than rats in groups Extinction during the period prior to the shock on day $3\left(F_{(1,21)}=13.097 ; P<0.05\right)$ (data not shown), this shocked 
A

\begin{tabular}{|lccccc|}
\hline \multicolumn{1}{|c}{ Groups } & Day 1 & Day 2 & Day 3 & Day 4 & Day 5 \\
$\begin{array}{l}\text { Extinction } \\
\text { (Ext) }\end{array}$ & + & & + & Vehicle or lfenprodil & - \\
\hline $\begin{array}{l}\text { Re-extinction } \\
\text { (Re-ext) }\end{array}$ & + & - & + & Vehicle or lfenprodil & - \\
\hline
\end{tabular}

B

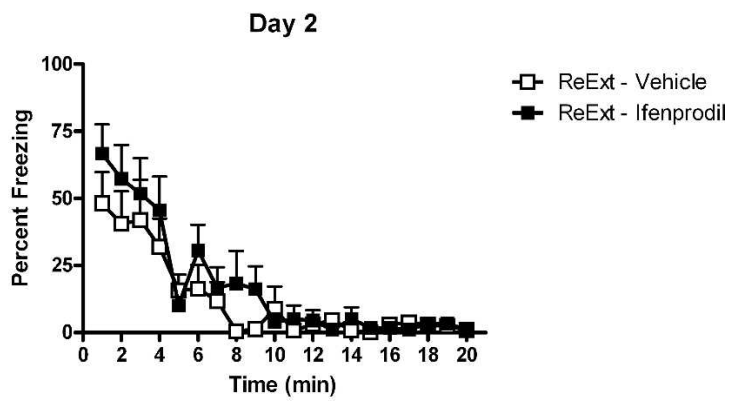

C

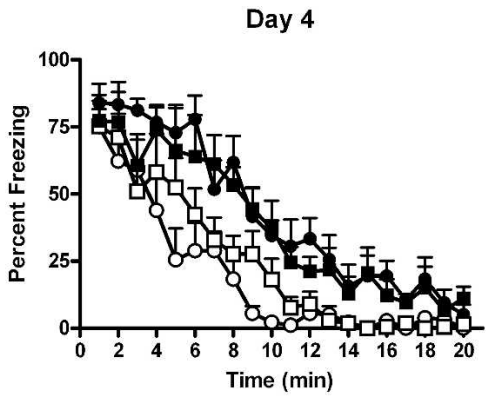

$$
\begin{aligned}
& \text { - - Ext - Vehicle } \\
& \rightarrow \text { Ext - Ifenprodil } \\
& \text { ㅁ ReExt - Vehicle } \\
& \rightarrow \text { ReExt - Ifenprodil }
\end{aligned}
$$

D

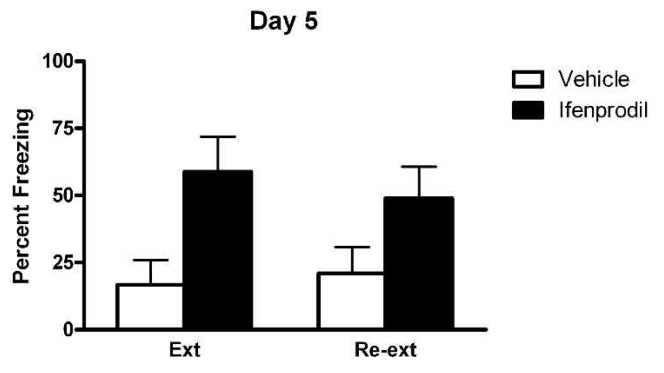

Figure 6. BLA infusion of ifenprodil impairs both learning and relearning extinction. $(A)$ Description of the behavioral procedures used in Experiment $5(+$, shocked exposure to the chambers; - , nonshocked exposure to the chambers). (B) All illustrations show the mean and SEM levels of freezing. Rats in groups Re-extinction lost freezing responses across extinction. (C) Ifenprodil maintained freezing responses across extinction and re-extinction. $(D)$ The retention test showed that ifenprodil impaired learning and relearning extinction. Retention of extinction and re-extinction learning was similar in control rats.

exposure restored extinguished fear responses. On day 4, there were no differences in the level of freezing between rats in groups Extinction-Vehicle and Re-extinction-Vehicle $\left(F_{(1,21)}=1.006\right.$; $P>0.05$ ) (Fig. 6C). Importantly, ifenprodil did not suppress fear reactions during extinction or re-extinction. Rather, rats under ifenprodil froze significantly more than vehicle-treated rats (groups Extinction-Ifenprodil and Re-extinction-Ifenprodil vs. groups Extinction-Vehicle and Re-extinction-Vehicle, $\left.F_{(1,21)}=24.133 ; P<0.05\right)$. Clearly, ifenprodil impaired the shortterm loss of fear responses. There was a significant linear trend, showing that freezing declined in all groups across the session $\left(F_{(1,21)}=204.351 ; P<0.05\right)$. There was no significant difference between ifenprodil-treated rats that received one or two extinction sessions $\left(F_{(1,21)}=0.543 ; P>0.05\right)$ or between rats treated with vehicle that received one or two extinction sessions $\left(F_{(1,21)}=1.006 ; P>0.05\right)$.

The test data from day 5 (Fig. 6D) showed that infusing ifenprodil in the BLA impaired learning extinction of fear responses. Rats in group Extinction-Ifenprodil exhibited more fear responses across test than rats in group Extinction-Vehicle $\left(F_{(1,21)}=38.680 ; P<0.05\right)$. Strikingly, a similar outcome was found when ifenprodil was infused prior to re-extinction training $\left(F_{(1,21)}=18.464 ; P<0.05\right)$. Vehicle-treated rats (groups Extinction-Vehicle and Re-extinction-Vehicle) displayed similar levels of freezing whether they received one or two extinction sessions $\left(F_{(1,21)}=0.409 ; P>0.05\right)$. Similarly, there were no significant differences between rats in groups Extinction-Ifenprodil and Reextinction-Ifenprodil $\left(F_{(1,21)}=2.139 ; P>0.05\right)$. Thus, ifenprodil impaired not only extinction but also re-extinction of fear responses.

\section{Discussion}

The present series of experiments examined the role of the BLA in learning and relearning extinction of context conditioned fear. The main finding is that re-extinction of fear responses can occur in the absence of activity in the BLA, in contrast to initial extinction, which requires that activity. Indeed, local infusion of the $\mathrm{GABA}_{\mathrm{A}}$ agonist muscimol impaired long-term extinction but left intact long-term re-extinction. The same infusion depressed fear responses across extinction training as well as across reextinction training (Experiment 4). This depression is consistent with the well-accepted view that activity in the BLA is critical for the expression of conditioned fear responses (Helmstetter and Bellgowan 1994; Muller et al. 1997; Lee and Kim 1998; Lee et al. 2001; Maren et al. 2001; Wilensky et al. 2006).

Local infusion of DL-APV, a competitive antagonist of NMDAr, exerted similar effects to muscimol-induced inactivation of the BLA. Rats treated with the NMDAr antagonist exhibited less fear responses than controls across extinction training but substantially more fear when subsequently tested drug free (Experiment 1). The deficit in fear responding across extinction training suggests that DL-APV blocked basal transmission in the BLA (Li et al. 1995; Maren and Fanselow 1995; Bauer et al. 2002). Thus, the impairment of long-term extinction may be caused by a disruption of neuronal activity in the BLA, similar to the one produced by muscimol, rather than a specific antagonism of NMDAr-dependent synaptic plasticity (Lee and Kim 1998; Lee et al. 2001). Interestingly, our results reveal once again that such disruption failed to impair long-term re-extinction. Rats infused with DL-APV in the BLA froze substantially less than controls across re-extinction training (Experiment 1). However, all rats exhibited similar levels of fear when subsequently tested drug free (Experiment 1). These data strongly suggest that local infusion of DL-APV or muscimol disrupts neuronal activity in the BLA that is necessary for learning but not for relearning extinction of conditioned fear.

Importantly, the immunity of relearning extinction to a disruption of neuronal activity in the BLA depends upon the initial extinction learning. When DL-APV was infused during the first extinction session training, rats failed to acquire re-extinction under DL-APV (Experiment 2). This indicates that the infusion of 
DL-APV during the first extinction session cancelled the effects of this session, in the sense that re-extinction became functionally equivalent to a first extinction. Moreover, DL-APV was shown to have no effect by itself if not infused during re-extinction (Experiment 1). Thus, the failure of DL-APV to affect relearning extinction depended on rats having learned extinction and on being subjected to re-extinction training under the influence of the drug. Moreover, we have also demonstrated that re-conditioning is not required for re-extinction to be immune to DL-APV infusion (data not shown).

The results presented so far contrast with those obtained with ifenprodil, a selective antagonist of NMDAr containing the NR2B subunit. Specifically, rats infused in the BLA with ifenprodil took longer to inhibit fear responses than control rats across both extinction and re-extinction training (Experiment 5). Moreover, those ifenprodil-treated rats showed higher levels of fear than controls when subsequently tested without the drug (Experiment 5). Fear responses were preserved by ifenprodil as reported in other studies (Rodrigues et al. 2001; Sotres-Bayon et al. 2007), indicating that it spares basal synaptic transmission in the amygdala (Bauer et al. 2002). Thus, a selective inactivation of NMDAr containing the NR2B subunit in the BLA disrupts not only learning extinction (Sotres-Bayon et al. 2007) but also relearning extinction of conditioned fear responses provided that basal synaptic transmission is preserved. In addition, the ability of ifenprodil to impair the short-term loss of fear responses indicates that NMDAr containing the NR2B subunit are involved in the acquisition of learning and relearning extinction (SotresBayon et al. 2007).

The present experiments therefore lead to the apparently paradoxical conclusion that selectively disrupting synaptic plasticity with ifenprodil had more dramatic effects on re-extinction training than disrupting both plasticity and neuronal activity with DL-APV or muscimol. To reconcile these findings, we propose that (1) relearning extinction normally requires NMDArdependent synaptic plasticity in the BLA but that (2) disruption of both plasticity and neuronal activity in the BLA results in some compensatory learning that can promote long-term reextinction. Importantly, this compensatory learning should not occur when basal synaptic activity in the BLA is preserved. Admittedly we cannot exclude the possibility that some of the effects of ifenprodil could be due to its selectivity toward the NR2B subunit, but it seems likely that the preservation of neuronal activity in the BLA is a more critical factor. Compensatory learning during re-extinction requires initial extinction learning (Experiment 2) that survives additional pairing of the CS with the US (Bouton and Swartzentruber 1989; Rescorla 2001). Therefore, we also propose that (3) the compensatory learning involves reactivating and strengthening the initial extinction learning stored in and expressed by other neural substrates than the BLA.

This hypothesis is supported by the results of Experiment 3. Brief re-extinction training is less efficient than long reextinction training under control conditions (i.e., vehicle), but it was shown to be as efficient as long re-extinction training when performed under an infusion of DL-APV (Experiment 3). This remarkable facilitation of re-extinction is readily explained if the re-extinction session under DL-APV simply reactivates and strengthens the initial extinction learning. Nevertheless, the behavioral procedure used in this study may allow an alternative interpretation. When reactivated, memories enter into a labile state, during which they are sensitive to inhibition of protein synthesis and various molecular changes (Dudai 2004; Dudai and Eisenberg 2004). This phase of reconsolidation is typically investigated by subjecting memories to a brief retrieval session similar to the brief re-extinction session we used. Therefore, DL-APV could have blocked the reconsolidation of the reconditioned fear memory, which would have resulted in very little levels of fear during subsequent test. However, BLA infusion of NMDAr antagonists has been shown to impair the retrieval but not the reconsolidation of reactivated fear memories (Ben Mamou et al. 2006). Furthermore, there would be no clear reason for reextinction to differ from extinction in this respect, considering that disrupting the reconsolidation of extinction should enhance rather than reduce fear. It is thus unlikely that a blockade of reconsolidation could explain our main result.

Nevertheless, the mechanisms triggering compensatory learning remain unclear. One possible explanation relies on the distinct behaviors displayed by rats across re-extinction training under DL-APV or ifenprodil. Indeed, DL-APV and muscimol depressed fear responses, whereas ifenprodil impaired the shortterm loss of these responses. Furthermore, the level of fear responses across extinction training has been shown to influence the learning produced by this training (Holland and Rescorla 1975; Rescorla 1997; Krupa and Thompson 2003). It is then possible that the absence of fear responses across re-extinction training could constitute a background similar to the background (i.e., absence of fear) at the end of extinction training, thereby allowing retrieval of the extinction memory (Bouton et al. 2006). Therefore, the loss of fear under DL-APV or muscimol would reactivate and strengthen the initial learning. Such compensatory learning would be able to promote long-term re-extinction and could also explain why a brief re-extinction session under DL-APV can be as efficient as a longer re-extinction session to retrieve and strengthen the initial learning. Conversely, since fear responding is preserved under ifenprodil, re-extinction training should fail to reactivate the original extinction learning. This mechanism is clearly speculative, and additional research is required. For instance, the inhibition of activity in the periaqueductal gray, which mediates the freezing responses (Kim et al. 1993; Behbehani 1995), would be useful in studying the role played by conditioned responding in learning and relearning extinction.

Regardless of a possible role for fear expression, compensatory learning by other neural substrates implies that the extinction memory is not exclusively stored in the BLA. This is consistent with the current neural model of fear extinction (Quirk et al. 2006; Quirk and Mueller 2007) that involves interactions between several structures including the BLA and the mPFC. In addition to its key role in fear learning and fear expression (Maren 2001; Rodrigues et al. 2004), the BLA appears necessary for the acquisition and the consolidation of extinction memory (Lin et al. 2003; Herry and Mons 2004; Herry et al. 2006; Kim et al. 2007; Sotres-Bayon et al. 2007). Activity in the mPFC is not critical for the acquisition of extinction memory but appears important for its consolidation and expression (Milad and Quirk 2002; Barrett et al. 2003; Herry and Mons 2004; Hugues et al. 2004, 2006; Santini et al. 2004; Burgos-Robles et al. 2007). Moreover, electrical stimulation of the mPFC reduces the expression of conditioned fear (Milad et al. 2004) and the activity of central amygdala (CeA) efferent neurons mediating this expression (Quirk et al. 2003). Therefore, the model assumes that during extinction, the mPFC controls the activation of inhibitory mechanisms in the CeA that suppress fear responses to the extinguished CS. This inhibition counteracts the activation of the CeA by the BLA via projections of the MPFC to a network of inhibitory interneurons located between the BLA and the CeA (Pare and Smith 1993a,b; McDonald et al. 1996; Royer et al. 1999). Consistent with this model, our results show that the acquisition of extinction requires activation of NMDAr containing the NR2B subunit and neuronal activity in the BLA. Relearning extinction under normal conditions appears to engage similar mechanisms as learning extinction. Yet, the learning produced 
by extinction training is thought to be stored in and expressed by the mPFC. Moreover, the initial extinction learning is not eliminated by the CS-US pairing administered subsequent to extinction training (Bouton and Swartzentruber 1989; Rescorla 2001). Thus, blockade of NMDAr containing the NR2B subunit and disruption of neuronal activity in the BLA will result in compensatory learning that may be supported by the mPFC. Neurons in the mPFC might be activated across re-extinction training in contrast to extinction training (Herry and Garcia 2002; Milad and Quirk 2002), thereby allowing the mPFC to re-exert its inhibitory influence on CeA efferent neurons when neuronal activity in the BLA is disrupted across brief or long re-extinction training. This could explain the strengthening of the initial extinction learning stored in the mPFC and the expression of long-term re-extinction.

In summary, the present experiments demonstrated that activation of NMDAr containing the NR2B subunit is normally required for the acquisition and the re-acquisition of short- and long-term extinction. However, long-term re-extinction may be acquired through some compensatory learning mechanism when both NMDAr dependent synaptic plasticity and neuronal activity in the BLA are disrupted across re-extinction training. The $\mathrm{mPFC}$ is a putative structure underlying such compensatory learning. Future experiments will be necessary to determine the role played by the MPFC in learning and relearning extinction of conditioned fear. These results may have important implications in the field of clinical research concerning the extinction of pathological fear in humans (Milad et al. 2006; Myers and Davis 2007). Indeed, they suggest that although the initial acquisition of extinction may be hindered by drugs that suppress fear responses, extinction could actually benefit from such drugs during subsequent sessions.

\section{Materials and Methods}

\section{Subjects}

Subjects were 191 experimentally naïve male Wistar rats (Rattus norvegicus). They were obtained from a local supplier (Gore Hill Research Laboratories, Sydney, New South Wales, Australia) and weighed between 250 and $350 \mathrm{~g}$. They were housed in plastic boxes $(22 \mathrm{~cm}$ high $\times 65 \mathrm{~cm}$ long $\times 40 \mathrm{~cm}$ wide) located in a climate-controlled colony room under natural lighting. There were eight rats per box with food and water available ad libitum. Three days after arrival in the laboratory, rats were handled each day for $4 \mathrm{~d}$. The experimental procedures were approved by the Animal Ethics Committee at the University of New South Wales and conducted in accordance with the National Institutes of Health Guidelines for the Care and Use of Laboratory Animals (publication DHHS NIH 86-23). All experiments took place between $0700 \mathrm{~h}$ and $1800 \mathrm{~h}$.

\section{Drugs}

The selective NMDAr antagonist DL-APV (Sigma), and the $\mathrm{GABA}_{\mathrm{A}}$ agonist muscimol (Sigma) were dissolved in nonpyrogenic saline $(0.9 \% \mathrm{w} / \mathrm{v})$ to obtain a final concentration of 2.5 $\mu \mathrm{g} / 0.3 \mu \mathrm{L}$ (DL-APV) and $0.3 \mu \mathrm{g} / 0.3 \mu \mathrm{L}$ (muscimol). Nonpyrogenic saline was used as a vehicle for experiments studying the effects of DL-APV and muscimol. Ifenprodil, a selective antagonist that blocks the NR2B subunit of NMDAr (Sigma), was dissolved in DMSO (dimethylsulfoxide; Sigma) and diluted in a solution of $0.9 \%$ nonpyrogenic saline $(\mathrm{w} / \mathrm{v})$ containing 5\% DMSO and $9 \%$ Tween 80 . This latter solution was used as a vehicle. Ifenprodil was microinjected into the BLA at a concentration of $1 \mu \mathrm{g} / 0.3 \mu \mathrm{L}$.

\section{Surgery and drug infusion}

Rats received i.p. injections of $1.3 \mathrm{~mL} / \mathrm{kg}$ of the anesthetic ketamine (Ketapex; Apex Laboratories) at a concentration of $100 \mathrm{mg} /$ $\mathrm{mL}$ and of $0.3 \mathrm{~mL} / \mathrm{kg}$ of the muscle relaxant xylazine (Rompun; Bayer) at a concentration of $20 \mathrm{mg} / \mathrm{mL}$. Anaesthetized rats were then mounted on a stereotaxic apparatus (Kopf Instruments), and 26-gauge guide cannulae (Plastics One) were implanted through holes drilled in both hemispheres of the skull. The tips of the guide cannulae were aimed bilaterally at the BLA using the following coordinates: $2.3 \mathrm{~mm}$ posterior to bregma, $4.8-5 \mathrm{~mm}$ lateral to the midline, and 7.7-8 ventral to the skull. The guide cannulae were maintained in position with dental cement, and dummy cannulae were kept in each guide at all times except during microinjections. Immediately after the surgical procedure, rats were injected i.p. with a prophylactic $(0.3 \mathrm{~mL})$ dose of $300 \mathrm{mg} / \mathrm{kg}$ solution of procaine penicillin. Rats were allowed $4 \mathrm{~d}$ to recover from surgery, during which time they were handled and weighed daily.

DL-APV $(2.5 \mu \mathrm{g} / 0.3 \mu \mathrm{L})$, muscimol $(0.3 \mu \mathrm{g} / 0.3 \mu \mathrm{L})$, ifenprodil $(1 \mu \mathrm{g} / 0.3 \mu \mathrm{L})$, or vehicle was infused bilaterally in the BLA by inserting a 33-gauge internal cannulae into the guide cannulae. The internal cannulae was connected to a 25 all-glass syringe attached to an infusion pump (Harvard Apparatus) and projected an additional $1 \mathrm{~mm}$ ventral to the tip of the guide cannulae. A total volume of $0.3 \mu \mathrm{L}$ was delivered to both sides at a rate of 0.1 $\mu \mathrm{L} / \mathrm{min}$. The internal cannulae were left in place for a further 1 min after the infusions. On the day before infusions, the dummy cannulae were removed and the infusion pump was turned on for $3 \mathrm{~min}$ in order to familiarize the rats with the procedure and thereby minimize any stress produced by this procedure when infusions occurred.

\section{Histology}

Subsequent to behavioral testing, subjects received a lethal dose of sodium pentobarbital. The brains were removed and sectioned coronally at $40 \mu \mathrm{m}$ through the BLA. Every third section was collected on a slide, and the sections were stained with cresyl violet. The location of cannulae tips was determined under a microscope by a trained observer who was unaware of the subjects' group designations using the boundaries defined by Paxinos and Watson's atlas (Paxinos and Watson 2007). Subjects with inaccurate cannulae placements or with extensive damage to the BLA were excluded from the statistical analysis.

\section{Apparatus}

Four chambers, each measuring $20 \mathrm{~cm}$ height $\times 21 \mathrm{~cm}$ length $\times 23 \mathrm{~cm}$ width, were used for pre-exposure, fear conditioning, extinction training, and testing. The front and rear walls of these chambers, as well as the hinged lid, were constructed of Perspex, and the end walls were made of stainless steel. The floor in each chamber consisted of stainless steel rods, $2 \mathrm{~mm}$ in diameter, spaced $10 \mathrm{~mm}$ apart (center to center). The US was a 1-sec, $0.5-\mathrm{mA}$ or a $1-\mathrm{sec}, 0.8-\mathrm{mA}$ unscrambled $\mathrm{AC} 50-\mathrm{Hz}$ foot shock from a constant-current generator that was delivered to the floor of each chamber. The current available to each floor could be adjusted using an in-line milliampere meter. The floor of each chamber was $5 \mathrm{~cm}$ above a tray of paper pellet bedding (Fibrecycle) that was changed between rats. After removal of a rat, the floor of each chamber was cleaned with a solution of acetic acid $(1 \%)$ to eliminate any residue and provide a distinctive odor. The four chambers were located within separate compartments of a wooden cabinet. The door of each compartment was kept open to permit observation of the rat.

The room that contained the experimental chambers was illuminated by four $60-\mathrm{W}$ standard incandescent lights located in the ceiling. All experimental sessions were recorded on videotapes via a camera mounted on a wall opposite the chambers. The camera was connected to a monitor and video recorder located in an adjacent room.

\section{Behavioral procedures}

\section{Experiment 1: BLA infusion of DL-APV impairs learning but not relearning extinction}

To minimize any deficits in conditioned fear responses due to the surgical procedure, all experiments included a pre-exposure phase. This consisted in exposing rats to the training chambers 
for 2 min each day across four consecutive days. Such exposure has been shown to facilitate the subsequent acquisition of fear reactions (Fanselow 1990; Kiernan and Westbrook 1993; Wiltgen et al. 2001). Following pre-exposure, on day 1, rats were placed in the chambers and shocked $(0.8 \mathrm{~mA} \times 1 \mathrm{sec}) 1 \mathrm{~min}$ later (Fig. $2 \mathrm{~A})$. They remained in the chamber for a further $2 \mathrm{~min}$ and were then returned to their home cages. On day 2 , rats in groups Reextinction and Control Re-Extinction received an extinction session that consisted of a 20-min exposure to the chamber in the absence of foot shock. Rats in groups Extinction did not receive an extinction session but were handled. On day 3, all rats received a second conditioning episode identical to the one described on day 1 . On day 4, rats in groups Extinction-APV, Reextinction-APV, and Control Re-Extinction-APV received an infusion of DL-APV $(2.5 \mu \mathrm{g} / 0.3 \mu \mathrm{L})$ into the BLA, whereas those in groups Extinction-Vehicle, Re-extinction-Vehicle, and Control Re-extinction-Vehicle received an infusion of saline. Immediately after infusion, rats in groups Extinction-APV, Reextinction-APV, Extinction-Vehicle, and Re-extinction-Vehicle received an extinction session identical to that on day 2 . Rats in groups Control Re-extinction-APV and Control Re-extinctionVehicle did not receive an extinction session but were handled. Six hours after this extinction session, rats that had been injected with saline now received an injection of DL-APV (groups Extinction-Vehicle and Re-extinction-Vehicle), and rats that had been injected with DL-APV now received an injection of saline (groups Extinction-DL-APV and Re-extinction-DL-APV). These counterbalancing infusions were used to control for any effects of DLAPV per se on responding across the subsequent test. On day 5 , all rats were tested for fear reactions in the chambers across a 10-min extinction session.

\section{Experiment 2: BLA infusion of DL-APV does not spare relearning extinction if initial extinction learning has been prevented}

In this experiment, infusions of either DL-APV or vehicle were given prior to each of the two extinction sessions (Fig. 3A). Following pre-exposure, on day 1 , rats were shocked in the chambers in the manner described. On day 2, rats in groups APVVehicle and APV-APV received an infusion of DL-APV into the BLA, whereas those in groups Vehicle-Vehicle and Vehicle-APV received an infusion of saline. All rats then received an extinction session that was the same as that described. Six hours later, rats received counterbalancing infusions of either vehicle or DL-APV. On day 3 , all rats were given a conditioning episode identical to that on day 1 . On day 4, rats in groups Vehicle-APV and APVAPV were infused with DL-APV into the BLA, whereas those in groups Vehicle-Vehicle and APV-Vehicle received an infusion of saline. Then all rats received an extinction session identical to that on day 2. Counterbalanced infusions were given $6 \mathrm{~h}$ later in the manner described. On day 5 , all rats were tested in the manner described.

\section{Experiment 3: BLA infusion of DL-APV facilitates relearning extinction}

This experiment manipulated the duration of the second extinction session performed under either DL-APV or vehicle (Fig. 4A). Following pre-exposure, on day 1 , all rats received a shocked exposure to the chambers in the manner described. On day 2 , all rats received an extinction session identical to that described. On day 3 , rats received a second conditioning episode identical to that on day 1 . On day 4 , half the rats were infused with DL-APV and half with vehicle. Then half the rats in each group were exposed to the chambers for $2 \mathrm{~min}$, whereas the other half was exposed for $20 \mathrm{~min}$ in the absence of shock. This resulted in four groups: group 2 min-Vehicle, group 2 min-APV, group 20 minVehicle, and group 20 min-APV. Six hours after this extinction session, counterbalancing infusions of either DL-APV or vehicle were performed. On day 5, all rats were tested in the chambers in the manner described.

\section{Experiment 4: BLA infusion of muscimol impairs learning but not relearning extinction}

This experiment attempted to replicate the effects from Experiment 1 using an inactivation with the $\mathrm{GABA}_{\mathrm{A}}$ agonist muscimol instead of DL-APV (Fig. 5A). Following pre-exposure, on day 1, rats were placed in the chambers and administered a foot shock in the manner described. On day 2, rats in groups Re-extinction received an extinction session that was the same as that described. Rats in groups Extinction did not receive an extinction session but were handled. On day 3 , all rats received a second conditioning episode identical to the one described on day 1 . On day 4, rats in groups Extinction-Muscimol and Re-extinctionMuscimol received an infusion of muscimol $(0.3 \mu \mathrm{g} / 0.3 \mu \mathrm{L})$ into the BLA, whereas those in groups Extinction-Vehicle and Reextinction-Vehicle received an infusion of saline. Twenty minutes after infusion, all rats received an extinction session identical to that on day 2. Six hours after this extinction session, counterbalancing infusions of either muscimol or vehicle were performed. On day 5, all rats were tested for fear reactions in the chambers across a 10 min extinction session.

\section{Experiment 5: BLA infusion of ifenprodil impairs both learning and relearning extinction}

The procedure in this experiment was identical to that in Experiment 5, except that ifenprodil, a specific antagonist against NMDAr containing the NR2B subunit, was used instead of muscimol (Fig. 6A). Following pre-exposure, on day 1, all rats received a shocked exposure to the chambers in the manner described. On day 2 , rats in groups Re-extinction received an extinction session that was the same as that described. On this day, rats in groups Extinction did not receive an extinction session but were handled. On day 3 , all rats received a conditioning episode identical to that on day 1. On day 4, rats in groups Extinction-Ifenprodil and Re-extinction-Ifenprodil received an infusion of ifenprodil $(1 \mu \mathrm{g} / 0.3 \mu \mathrm{L})$ into the BLA, whereas those in groups Extinction-Vehicle and Re-extinction-Vehicle received vehicle. Twenty minutes later, all rats received an extinction session identical to that on day 2 . Counterbalancing infusions were given $6 \mathrm{~h}$ later in the manner described. On day 5, all rats were tested in the manner described previously.

\section{Scoring and statistics}

Freezing was defined as the absence of all movements, except those related to breathing (Blanchard and Blanchard 1969). The behavior of each rat was recorded on videotape, and freezing was rated with a time-sampling procedure in which each rat was observed every $2 \mathrm{sec}$ and scored as either freezing or moving. A percentage score was calculated for the proportion of the total observation that each rat spent freezing. Freezing was rated by two observers, one of whom was unaware of the subject's group designation. There was a high degree of agreement between the two observers: The Pearson product moment correlation between their rating was $>0.95$. The data were analyzed in each experiment by a set of planned nonorthogonal contrasts that controlled the error rate using the Bonferroni inequality procedure. Significance was set at the 0.05 level.

\section{References}

Barrett, D., Shumake, J., Jones, D., and Gonzalez-Lima, F. 2003. Metabolic mapping of mouse brain activity after extinction of a conditioned emotional response. J. Neurosci. 23: 5740-5749.

Bauer, E.P., Schafe, G.E., and Ledoux, J.E. 2002. NMDA receptors and L-type voltage-gated calcium channels contribute to long-term potentiation and different components of fear memory formation in the lateral amygdala. J. Neurosci. 22: 5239-5249.

Behbehani, M.M. 1995. Functional characteristics of the midbrain periaqueductal gray. Prog. Neurobiol. 46: 575-605.

Ben Mamou, C., Gamache, K., and Nader, K. 2006. NMDA receptors are critical for unleashing consolidated auditory fear memories. Nat. Neurosci. 9: 1237-1239.

Blanchard, R.J. and Blanchard, D.C. 1969. Crouching as an index of fear. J. Comp. Physiol. Psychol. 67: 370-375.

Bouton, M.E. and Swartzentruber, D. 1989. Slow reacquisition following acquisition: Context encoding and retrieval mechanisms. J. Exp. Psychol. Anim. Behav. Process. 15: 43-53.

Bouton, M.E., Westbrook, R.F., Corcoran, K.A., and Maren, S. 2006 Contextual and temporal modulation of extinction: Behavioral and biological mechanisms. Biol. Psychiatry 60: 352-360. 
Burgos-Robles, A., Vidal-Gonzalez, I., Santini, E., and Quirk, G.J. 2007. Consolidation of fear extinction requires NMDA receptor-dependent bursting in the ventromedial prefrontal cortex. Neuron 53: 871-880.

Calandreau, L., Desmedt, A., Decorte, L., and Jaffard, R. 2005. A different recruitment of the lateral and basolateral amygdala promotes contextual or elemental conditioned association in Pavlovian fear conditioning. Learn. Mem. 12: 383-388.

Delamater, A.R. 2004. Experimental extinction in Pavlovian conditioning: Behavioural and neuroscience perspectives. Q. J. Exp. Psychol. B 57: 97-132.

Dudai, Y. 2004. The neurobiology of consolidations, or, how stable is the engram? Annu. Rev. Psychol. 55: 51-86.

Dudai, Y. and Eisenberg, M. 2004. Rites of passage of the engram: Reconsolidation and the lingering consolidation hypothesis. Neuron 44: 93-100.

Fanselow, M.S. 1990. Factors governing one trial contextual fear conditioning. Anim. Learn. Behav. 18: 264-270.

Helmstetter, F.J. and Bellgowan, P.S. 1994. Effects of muscimol applied to the basolateral amygdala on acquisition and expression of contextual fear conditioning in rats. Behav. Neurosci. 108: 1005-1009.

Herry, C. and Garcia, R. 2002. Prefrontal cortex long-term potentiation, but not long-term depression, is associated with the maintenance of extinction of learned fear in mice. J. Neurosci. 22: 577-583.

Herry, C. and Mons, N. 2004. Resistance to extinction is associated with impaired immediate early gene induction in medial prefrontal cortex and amygdala. Eur. J. Neurosci. 20: 781-790.

Herry, C., Trifilieff, P., Micheau, J., Luthi, A., and Mons, N. 2006. Extinction of auditory fear conditioning requires MAPK/ERK activation in the basolateral amygdala. Eur. J. Neurosci. 24: 261-269.

Holland, P. and Rescorla, R.A. 1975. The effects of two ways of devaluing the unconditioned stimulus after first- and second-order appetitive conditioning. J. Exp. Psychol. Anim. Behav. Process. 1: $355-363$.

Hugues, S., Deschaux, O., and Garcia, R. 2004. Postextinction infusion of a mitogen-activated protein kinase inhibitor into the medial prefrontal cortex impairs memory of the extinction of conditioned fear. Learn. Mem. 11: 540-543.

Hugues, S., Chessel, A., Lena, I., Marsault, R., and Garcia, R. 2006. Prefrontal infusion of PD098059 immediately after fear extinction training blocks extinction-associated prefrontal synaptic plasticity and decreases prefrontal ERK2 phosphorylation. Synapse 60: $280-287$.

Kiernan, M.J. and Westbrook, R.F. 1993. Effects of exposure to a to-be-shocked environment upon the rat's freezing response: Evidence for facilitation, latent inhibition, and perceptual learning. Q. J. Exp. Psychol. B 46: 271-288.

Kim, J.J., Rison, R.A., and Fanselow, M.S. 1993. Effects of amygdala, hippocampus, and periaqueductal gray lesions on short- and long-term contextual fear. Behav. Neurosci. 107: 1093-1098.

Kim, J., Lee, S., Park, H., Song, B., Hong, I., Geum, D., Shin, K., and Choi, S. 2007. Blockade of amygdala metabotropic glutamate receptor subtype 1 impairs fear extinction. Biochem. Biophys. Res. Commun. 355: 188-193.

Krupa, D.J. and Thompson, R.F. 2003. Inhibiting the expression of a classically conditioned behavior prevents its extinction. J. Neurosci. 23: 10577-10584.

Lee, H. and Kim, J.J. 1998. Amygdalar NMDA receptors are critical for new fear learning in previously fear-conditioned rats. J. Neurosci. 18: $8444-8454$.

Lee, H.J., Choi, J.S., Brown, T.H., and Kim, J.J. 2001. Amygdalar NMDA receptors are critical for the expression of multiple conditioned fear responses. J. Neurosci. 21: 4116-4124.

Leung, H.T., Bailey, G.K., Laurent, V., and Westbrook, R.F. 2007. Rapid reacquisition of fear to a completely extinguished context is replaced by transient impairment with additional extinction training. J. Exp. Psychol. Anim. Behav. Process. 33: 299-313.

Li, X.F., Phillips, R., and LeDoux, J.E. 1995. NMDA and non-NMDA receptors contribute to synaptic transmission between the medial geniculate body and the lateral nucleus of the amygdala. Exp. Brain Res. 105: 87-100.

Lin, C.H., Yeh, S.H., Lu, H.Y., and Gean, P.W. 2003. The similarities and diversities of signal pathways leading to consolidation of conditioning and consolidation of extinction of fear memory. $J$. Neurosci. 23: 8310-8317.

Maren, S. 2001. Neurobiology of Pavlovian fear conditioning. Annu. Rev. Neurosci. 24: 897-931.
Maren, S. and Fanselow, M.S. 1995. Synaptic plasticity in the basolateral amygdala induced by hippocampal formation stimulation in vivo. $J$. Neurosci. 15: 7548-7564.

Maren, S., Yap, S.A., and Goosens, K.A. 2001. The amygdala is essential for the development of neuronal plasticity in the medial geniculate nucleus during auditory fear conditioning in rats. J. Neurosci.

21: RC135. http://www.jneurosci.org/cgi/content/full/21/6/RC135.

McDonald, A.J., Mascagni, F., and Guo, L. 1996. Projections of the medial and lateral prefrontal cortices to the amygdala: A Phaseolus vulgaris leucoagglutinin study in the rat. Neuroscience 71: 55-75.

Milad, M.R. and Quirk, G.J. 2002. Neurons in medial prefrontal cortex signal memory for fear extinction. Nature 420: 70-74.

Milad, M.R., Vidal-Gonzalez, I., and Quirk, G.J. 2004. Electrical stimulation of medial prefrontal cortex reduces conditioned fear in a temporally specific manner. Behav. Neurosci. 118: 389-394.

Milad, M.R., Rauch, S.L., Pitman, R.K., and Quirk, G.J. 2006. Fear extinction in rats: Implications for human brain imaging and anxiety disorders. Biol. Psychol. 73: 61-71.

Muller, J., Corodimas, K.P., Fridel, Z., and LeDoux, J.E. 1997. Functional inactivation of the lateral and basal nuclei of the amygdala by muscimol infusion prevents fear conditioning to an explicit conditioned stimulus and to contextual stimuli. Behav. Neurosci. 111: 683-691.

Myers, K.M. and Davis, M. 2007. Mechanisms of fear extinction. Mol. Psychiatry 12: $120-150$.

Myers, K.M., Ressler, K.J., and Davis, M. 2006. Different mechanisms of fear extinction dependent on length of time since fear acquisition. Learn. Mem. 13: 216-223.

Pare, D. and Smith, Y. 1993a. Distribution of GABA immunoreactivity in the amygdaloid complex of the cat. Neuroscience 57: 1061-1076.

Pare, D. and Smith, Y. 1993b. The intercalated cell masses project to the central and medial nuclei of the amygdala in cats. Neuroscience 57: 1077-1090.

Paxinos, G. and Watson, C. 2007. The rat brain in stereotaxic coordinates. Academic Press, Sydney.

Quirk, G.J. and Mueller, D. 2007. Neural mechanisms of extinction learning and retrieval. Neuropsychopharmacology 33: 56-72.

Quirk, G.J., Likhtik, E., Pelletier, J.G., and Pare, D. 2003. Stimulation of medial prefrontal cortex decreases the responsiveness of central amygdala output neurons. J. Neurosci. 23: 8800-8807.

Quirk, G.J., Garcia, R., and Gonzalez-Lima, F. 2006. Prefrontal mechanisms in extinction of conditioned fear. Biol. Psychiatry 60: $337-343$.

Rescorla, R.A. 1997. Response-inhibition in extinction. Q. J. Exp. Psychol. B 50: $238-252$.

Rescorla, R.A. 2001. Retraining of extinguished Pavlovian stimuli. J. Exp. Psychol. Anim. Behav. Process. 27: 115-124.

Rodrigues, S.M., Schafe, G.E., and LeDoux, J.E. 2001. Intra-amygdala blockade of the NR2B subunit of the NMDA receptor disrupts the acquisition but not the expression of fear conditioning. J. Neurosci. 21: 6889-6896.

Rodrigues, S.M., Schafe, G.E., and LeDoux, J.E. 2004. Molecular mechanisms underlying emotional learning and memory in the lateral amygdala. Neuron 44: 75-91.

Royer, S., Martina, M., and Pare, D. 1999. An inhibitory interface gates impulse traffic between the input and output stations of the amygdala. J. Neurosci. 19: 10575-10583.

Sah, P., Faber, E.S., Lopez De Armentia, M., and Power, J. 2003. The amygdaloid complex: Anatomy and physiology. Physiol. Rev. 83: $803-834$.

Santini, E., Ge, H., Ren, K., Pena, D.O., and Quirk, G.J. 2004. Consolidation of fear extinction requires protein synthesis in the medial prefrontal cortex. J. Neurosci. 24: 5704-5710.

Sotres-Bayon, F., Bush, D.E., and Ledoux, J.E. 2007. Acquisition of fear extinction requires activation of NR2B-containing NMDA receptors in the lateral amygdala. Neuropsychopharmacology 32: 1929-1940.

Wilensky, A.E., Schafe, G.E., Kristensen, M.P., and LeDoux, J.E. 2006. Rethinking the fear circuit: The central nucleus of the amygdala is required for the acquisition, consolidation, and expression of Pavlovian fear conditioning. J. Neurosci. 26: 12387-12396.

Wiltgen, B.J., Sanders, M.J., Behne, N.S., and Fanselow, M.S. 2001. Sex differences, context preexposure, and the immediate shock deficit in Pavlovian context conditioning with mice. Behav. Neurosci. 115: $26-32$

Received January 23, 2008; accepted in revised form February 21, 2008 


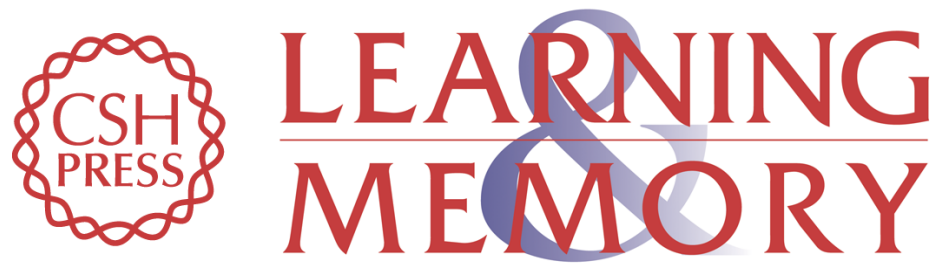

\section{The basolateral amygdala is necessary for learning but not relearning extinction of context conditioned fear}

Vincent Laurent, Alain R. Marchand and R. Frederick Westbrook

Learn. Mem. 2008, 15:

Access the most recent version at doi:10.1101//m.928208

References This article cites 54 articles, 17 of which can be accessed free at: http://learnmem.cshlp.org/content/15/5/304.full.html\#ref-list-1

License

Email Alerting Receive free email alerts when new articles cite this article - sign up in the box at the Service top right corner of the article or click here. 